\title{
3D Printing in the Learning Process of Furniture Design
}

\author{
Yulvan \\ Postgraduate Program of ISI Surakarta \\ yulvan@staff.uns.ac.id
}

\begin{abstract}
The development of technology is going fast and cannot be avoided. 3D printing technology exists that is capable of printing objects that are exactly the same as the soft file image in three-dimensional form. The existence of this technology affects the design work process. The learning for students in design has long used work patterns with hand-drawn sketches and creating the design manually, however technology has changed the design work since a few years ago that began with the use of design software. By the advance of 3D printing, students as potential designers can use this technology to develop spatial abilities in the creative process of design. The extent to which the design work process with technology can improve student's spatial ability and change design work patterns from manual to digital design. This research illustrates that $3 \mathrm{D}$ printing can make sustainable changes in the design process in increasing creativity and productivity, although the manual work process is still a component in design learning. The descriptive-analytic method with a phenomenological approach is used by observing the furniture design process by students using 3D printing. The formation of the pattern of student work by using this technology produces a new work culture.
\end{abstract}

Keywords: $3 D$ printing, design learning, the furniture design process

\section{INTRODUCTION}

3D printing is a new breakthrough in the world of technology. 3D printing technology is also known as additive manufacturing, where objects are created by stacking the bottom layers of materials and building them layer by layer. 3D printing is a rapid prototyping technology, physical modelling technology that can form a prototype more easily and quickly [1]. Prototyping is an initial embodiment of a design concept that has or will be developed from a product. The design process is carried out through several stages of design work, initially, the concept of ideas is made by hand sketching, then sketching alternative designs, manual work drawings up to making manual prototypes with the use of many tools, both cutting tools, dies, and molds. The process of making a manual prototype takes a long time and is difficult to realize complex shapes, even though this work pattern is still being carried out in the design learning process until now. Now, with 3D printing that has the ability to make design prototypes easier it will provide a new alternative media in design learning.

Visual form is a media created by students in expressing the aesthetic experiences of an idea or ideas. In the process of designing what is needed is not limited to logic of reasoning, 
but also the wildness of imagination and sharpness of intuition so that design can become a masterpiece and be able to inspire [2]. 3D printing is a digital technology to realize the imagination of ideas into three-dimensional visuals that are not limited by the level of complexity of the geometry, where conditions are difficult to do with manual work processes. Digital design work also enables new innovations to handle the complexity of form, function, material, and environment [2]. As has been done by designer Zaha Hadid in the design of Rise chair and Bowl chair, implementing digital processes and realizing his ideas through 3D printing technology. Thus, if the technology is applied in design learning, the extent of the design work process with $3 \mathrm{D}$ printing can change the design work patterns from manual to digital.

\section{METHOD}

This study uses a phenomenological approach with descriptive analysis methods concerning the use of technology that is developing at this time, especially in learning furniture design. Phenomenology is closely related to the knowledge of something to the extent that it manifests itself in experience [3]. Steps were taken by observing, interpreting and inferring the development of $3 \mathrm{D}$ printing and furniture design processes with these technologies.

\section{RESULT AND DISCUSSION}

One thing that is difficult to deny today is that contemporary humans are accompanied by technology everywhere [4]. Technology very much provides convenience and begins to be a part of all activities, one of which is 3d printing technology. Lots of things can be created with $3 \mathrm{D}$ printing in various fields, one of them is in furniture design. As this technology increases, there is an awareness that complex forms can be produced directly which cannot possibly be produced. Ismiati and Herianti [5] conclude based on the data of their research respondents that the use of $3 \mathrm{D}$ printing technology is currently dominated by many Javanese people and developing well in the industrial and socio-cultural sectors.

\subsection{D printings in Indonesia}

3D printing which is also called additive manufacturing or rapid prototyping has several classifications that are distinguished from raw materials and the mechanism for making them. FFF (Fused Filament Fabrication) is 3D printing that uses plastic raw materials such as cable reels which are later thawed and formed. SLA (Stereolithography) 3D printing uses resin as its raw material, this resin is sensitive to light so that the resin is able to harden to make the desired shape. SLS (Selective Laser Sintering) is a classification of 3D printers made from powder (plastic or metal powder), and as the name implies is made by heating the powder with a laser layer by layer. A 3D printer that has developed in Indonesia is FFF where raw materials are cheap and now this technology is available in the market at varying prices. Important changes occurred with the increasingly affordable technology in society, 3D printing is not only available as a specialist service but for the general public. This facilitates the making of an individual product in homes so that it can change the land of production and consumption. With manufacturing capabilities distributed to consumers and if in the future anyone can have the capacity to design particular product design, resources to buy computers and 3D printing, how is the extent of development in the future design world? 
It is likely that this will have an impact on design education now and in the future. As stated by William J. Mitchell [6], technology now plays an important role in the formation and sustainable competitiveness of creative activities.

Changes to the digital direction will soon be faced, like it or not, and not ready in various fields, therefore in this case students as prospective designers must prepare themselves to face challenges ahead. Hyun-Dae Kang in his research stated that the competitiveness of 3D printing techniques awakens the furniture industry, which generates a small production of personal tastes so that custom designs are made possible, digital changes are made easier, furniture design manufacturing breakthroughs where there is a room for 'smart furniture design' development with the mixing of $3 \mathrm{D}$ printing and internet of things, as well as consistently eco-friendly furniture design methods [7]. Based on this, 3D printing is very important to use in the furniture design process now and in the future. Universities in Indonesia which have interior design and product design study programs have introduced this technology to students as knowledge in exploring forms and realizing designs. Based on tempo.co on April 1, 2015, at Pelita Harapan University, Tangerang, 3D printers are used in rapid prototyping courses by second-year students of the School of Design faculty majoring in product design. Interior Design Study Program Sebelas Maret University Surakarta has also applied this technology in furniture design courses as an option in the process of prototyping furniture design in addition to a manual process, allowing students to make prototypes with digital processes, as well as alternatives in making complex shapes as solutions to problems or individual needs in furniture design. The learning activities of the two universities show that technology has begun to be applied in the design learning process in Indonesia.

\subsection{The furniture design process}

The furniture design process is a systematic step in designing furniture. There are 6 main stages in the design process namely (1) Conceptualization, (2) Research, (3) Design development, (4) Implementation, (5) Evaluation, (6) Presentation [8]. Conceptualization and research developed from the initial idea of the formulation of the problem and the collection of information carried out for the concept plan outlined in the form of sketches and alternative designs. Development and implementation activities are the solutions of structural aesthetic problems and functions of forms, analysing, and perfecting designs in expressing concepts, carried out through work drawings and prototypes. Evaluation is done through criticism of the design results that are realized, whether in terms of function, aesthetics, and ergonomics. The creativity and quality of design work are presented which will ultimately help in building a reputation and increase the selling power of the design, through the presentation media needed, one of which is prototyping.

The furniture design process through several stages of design requires a short amount of time, with a manual process at first the concept of an idea is made by hand sketching, then sketching alternative designs, manual working drawings up to making manual prototypes with the use of many tools, both cutting tools, forming as well as tools for assembling. If there is no conformity, the design process starts from the beginning again until finding the desired final design. While the furniture design process with $3 \mathrm{D}$ printing technology cuts several design stages, after the concept of the idea of the problem is planned in a rough sketch, the design is made directly in a computer model with a CAD (Computer-Aided Design) file using a program (3D max, AutoCAD, etc.) that allows users to design and modify three-dimensional furniture designs on a computer. Designs in digital files will be easily printed with $3 \mathrm{D}$ printing anytime, anywhere [9]. CAD files also allow verification in furniture design before printing so 
as to reduce errors and make repairs. Barry Berman [10] also states that all 3D printers use 3D CAD software that can measure thousands of cross-sections of each object to determine how each layer will be built correctly. This technology can make all the simple shapes you want to print very complicated shapes, some of which are impossible using manual techniques.

The application of 3D printing in design learning provides an alternative for students to choose the media they will use in making furniture designs based on their creative imagination concepts. Changes that are driven by innovation in science and technology can also occur in the world of education, especially higher education [11]. As did the interior design students of Sebelas Maret University, some chose to do digital design work that was more practical in the complexity of making and improving the design. The selection of furniture design processes with 3D printing by these students made changes in new work patterns in the design. The Royal Academy of Engineering [12] states that additive manufacturing not only changes conventional manufacturing processes, but this technology also allows the formation of new products and new businesses that are more advanced. If so the digital work culture has begun.

\section{CONCLUSION}

Furniture design by applying a 3D printing system is advantageous in terms of production, allowing objects to be made without tools, thus saving time in making prototypes where the object is made just once with a CAD file. In making geometric shapes with a high degree of difficulty it is easier than the manual manufacturing process because it is through a computerized technological process so that it is easy to make improvements. This makes the costs incurred much cheaper. From the side of students as prospective designers more free to experiment with complicated forms that are useful in realizing the imagination of ideas in solving problems in furniture design. This technology changes the pattern of design work done by students because of the ability to produce complex objects and overcome the lead time design process. The sustainable implementation of this technology in the furniture design learning process creates a new work culture, the student work culture uses 3D printing in the furniture design process, no longer uses the manual work process in prototyping. Creating a work culture of digital furniture design through $3 \mathrm{D}$ modeling, prototyping $3 \mathrm{D}$ printing, and the process of reviewing, repeating and improving design digitally. The furniture design prototype with $3 \mathrm{D}$ printing is a concrete manifestation of this new culture.

\section{REFERENCES}

[1] J. Lindley, R. Adams, J. Beaufoy, dan S. McGonigal, "A traditional approach to 3D printing," Int. Conf. Eng. Prod. Des. Educ. E\&PDE14, no. September, hal. 555-560, 2014.

[2] T. Rahayu, "Desain dan Ruhnya Kini," in Untuk Apa Seni?, B. Sugiharto, Ed. Bandung: Pustaka Mandiri, 2013, hal. 142-169.

[3] M. Farid, FENOMENOLOGI Dalam Penelitian Ilmu Sosial, Pertama. Jakarta: Prenadamedia Group, 2018.

[4] O. Drianus, "Manusia di Era Kebudayaan Digital: Interpretasi Ontologis Martin Heidegger," J. Dakwah dan Pengemb. Sos. Kemanus., vol. 9, no. 2, hal. 178-199, 2018.

[5] H. Ismianti, "FRAMEWORK PREDIKSI PENGGUNAAN 3D PRINTING DI INDONESIA PADA TAHUN 2030," Semin. Nas. IENACO, no. 2013, hal. 546-553, 2018.

[6] W. J. Mitchell, A. S. Inouye, dan M. S. Blumenthal, Beyond Productivity, Information Technology, Innovation and Creativity. Washington D.C.: The National Academies Press., 2003.

[7] H.-D. Kang, “Analysis of Furniture Design Cases Using 3D Printing Technique,” J. Korea Contents Assoc., vol. 15, no. 2, hal. 177-186, 2015.

[8] M. Sholahuddin, PROSES PERANCANGAN DESAIN MEBEL. Yogyakarta: Badan Penerbit ISI 
Yogyakarta, 2014.

[9] H. Stahl, "3D Printing - Risks and Opportunities," Inst. Appl. Ecol., no. December, 2013.

[10] B. Berman, "3-D printing: The new industrial revolution," Bus. Horiz., vol. 55, no. 2, hal. 155$162,2012$.

[11] B. Lian, "REVOLUSI INDUSTRI 4.0 DAN DISRUPSI, TANTANGAN DAN ANCAMAN BAGI PERGURUAN TINGGI," Pros. Semin. Nas. Pendidik. Progr. Pascasarj. Univ. PGRI Palembang, hal. 40-45, 2019.

[12] R. A. of Engineering, Additive manufacturing : opportunities and constraints. London: Royal Academy of Engineering, 2013. 